\title{
Long-Term Follow-Up Results of Ultrasound-Guided Radiofrequency Ablation for Low-Risk Papillary Thyroid Microcarcinoma: More Than 5-Year Follow-Up for 84 Tumors
}

\author{
Se Jin Cho, ${ }^{1,2}$ Sun Mi Baek, ${ }^{3}$ Hyun Kyung Lim, ${ }^{4}$ Kang Dae Lee, ${ }^{5}$ Jung Min Son, ${ }^{3}$ and Jung Hwan Baek ${ }^{1}$
}

\begin{abstract}
Background: Despite reports describing favorable short-term results for thermal ablation of thyroid cancer, there remains a need to evaluate long-term results because of its indolent characteristics. The purpose of this study was to evaluate the long-term efficacy and safety of ultrasound (US)-guided radiofrequency ablation (RFA) for low-risk papillary thyroid microcarcinoma (PTMC) over a follow-up period of more than five years. Methods: From a cohort of patients under surveillance after US-guided RFA for primary low-risk PTMC, those with a record of follow-up data of more than five years were selected for this study. Before RFA, all patients underwent US and computed tomography to evaluate the PTMC and the presence of neck metastasis. RFA was performed using thyroid-dedicated electrodes. Follow-up US was performed 6 and 12 months after initial RFA, and then every 12 months. The status of ablated tumors was evaluated according to volume reduction, local tumor progression, newly developed cancers, lymph node (LN) or distant metastasis, and delayed surgery during follow-up. Complications during the procedure and follow-up period were evaluated.

Results: A total of 84 nodules from 74 patients were included in this study. All patients tolerated RFA, and the mean follow-up duration was 72 months. After RFA, complete disappearance rates of $98.8 \%$ and $100 \%$ were achieved at 24 and 60-month follow-up, respectively. Additional ablations were performed in 13 of 84 tumors. The mean number of RFA sessions was 1.2. There were four newly developed cancers in three patients, and these were also treated with RFA and completely disappeared. During the follow-up period, there was no local tumor progression, no LN or distant metastasis, and no patients underwent delayed surgery. The major complication rate was $1.4 \%(1 / 74)$, and there was no delayed complication or procedure-related death.

Conclusions: RFA is effective for treating low-risk PTMC patients, without occurrence of local tumor progression, LN or distant metastasis, delayed complications, procedure-related death, or delayed surgery over more than five years of follow-up.
\end{abstract}

Keywords: radiofrequency ablation, papillary thyroid microcarcinoma, ultrasound, long-term, efficacy, safety

\section{Introduction}

A CTIVE SURVEILLANCE (AS) HAS BEEN adopted as a new option for low-risk papillary thyroid microcarcinoma (PTMC), even though surgery remains the standard treatment it may be associated with complications (1). Although AS has shown promising results, the proportion of delayed surgeries is substantial (3.4-32\%) (2-5). Furthermore, a recent sys- tematic review and meta-analysis reported that patient anxiety was the reason for a large proportion (32-69\%) of patients having delayed surgeries, not disease progression (6).

Recently, ultrasound (US)-guided thermal ablation has shown excellent results as an alternative treatment option for low-risk PTMC. In two recent systematic reviews and metaanalyses, thermal ablation revealed a mean volume reduction of $98.1 \%$ and a lymph node (LN) metastasis rate of only

\footnotetext{
${ }^{1}$ Department of Radiology and Research Institute of Radiology, University of Ulsan College of Medicine, Asan Medical Center, Seoul, Republic of Korea.

${ }^{2}$ Department of Radiology, Seoul National University College of Medicine, Seoul National University Bundang Hospital, Seongnam, Republic of Korea.

${ }^{3}$ Department of Radiology, Haeundae Sharing and Happiness Hospital, Busan, Republic of Korea.

${ }^{4}$ Department of Radiology, Soonchunhyang University Seoul Hospital, Seoul, Republic of Korea.

${ }^{5}$ Department of Otolaryngology-Head and Neck Surgery, Kosin University College of Medicine, Busan, Republic of Korea.
} 
$0.4 \%$, without local tumor recurrence or distant metastasis $(7,8)$. According to a recent meta-analysis, the results of thermal ablation seem to be similar or slightly superior to those of AS, with AS showing a 6.7\% mean size enlargement at 5 years, and a rate of $1.6 \%$ for LN metastasis over 5 years (6). Moreover, the differences in the number of patients undergoing delayed surgery are prominent, with a systematic review reporting a delayed surgery rate of only $1.1 \%$ in patients undergoing thermal ablation, including three patients with unknown etiology other than LN metastasis (7). However, direct comparisons are limited because of a lack of paired comparisons, and the follow-up periods are relatively short for thermal ablation than for AS $(6,7)$.

Therefore, there is a need to report the long-term follow-up results of thermal ablation to permit accumulation of sufficient data to allow comparisons between the different management options for low-risk PTMC. The purpose of this study was to evaluate the efficacy and safety of radiofrequency ablation (RFA) for low-risk PTMC in a cohort with ongoing postprocedural surveillance and follow-up data of more than five years.

\section{Materials and Methods}

This retrospective study was approved by our institutional review boards, and written informed consent was obtained from all patients before RFA.

\section{Study population}

Our group previously published a study (mean follow-up, 39 months) on the US-guided RFA of 152 primary low-risk PTMCs (size, 0.3-1 cm) in 133 patients performed between September 2008 and January 2017 (9). From the cohort still undergoing postprocedural surveillance, those patients with follow-up data covering more than five years were identified. The inclusion criteria were as follows: confirmation of the absence of aggressive pathology on pre-RFA fine needle aspiration (FNA) cytology $(10,11)$; no evidence of gross extrathyroidal extension on US and computed tomography (CT) $(5,12)$; and contraindications for surgery (including old age $>80$ years; comorbidity such as cardiovascular disease, history of stroke, central nervous system vascular malformation, other malignancy, and immunocompromised state) or refused surgery. The exclusion criteria were as follows: thyroid cancer with gross extrathyroidal extension, LN metastasis (either radiological or cytological evidence), distant metastasis, and pregnancy (9). This retrospective study included 84 PTMCs in 74 patients.

\section{Pre-RFA assessment}

All patients underwent pre-RFA assessment US examinations using either iU22US (Philips Healthcare, Bothell, WA, USA) or EUB-7500 (Hitachi Medical Systems, Tokyo, Japan) systems equipped with a linear high-frequency probe $(5-14 \mathrm{MHz})$. The orthogonal three-dimensional maximal diameters and tumor volume of each nodule were evaluated on the US examination. The volume of each tumor was calculated as $V=\pi a b c / 6$ (where $V$ is the volume, $a$ is the largest diameter, and $b$ and $c$ are the two other perpendicular maximal diameters) (13). After evaluation of the PTMC itself, a screening neck US was performed to detect the presence of
LN metastasis. For cytopathological confirmation, US-guided FNA was performed after the US examination (11).

Contrast-enhanced neck CT was acquired from all patients to exclude LN or distant metastasis. Routine laboratory examinations, including thyroid function test, serum thyroglobulin, thyroglobulin antibody, platelet count, and blood coagulation tests, were also performed.

All patients' radiological evaluations, such as US and CT images, and the results of their laboratory tests were reviewed by a radiologist (S.M.B.) with 19 years of experience in thyroid imaging.

\section{RFA procedure}

All RFA procedures were performed by one expert radiologist (S.M.B.; 13 years of experience with thyroid RFA) on an outpatient basis. An 18-gauge thyroid-dedicated internally cooled electrode and $0.5,0.7$, and $1 \mathrm{~cm}$ active tips were used, depending on the size of the targeted tumor (14). Detailed information on the equipment was provided in a prior report (9). A supine position with neck extension was the routine posture for the patients. To prevent bleeding, the detailed vascular anatomy along the approach route was evaluated by Doppler US. The relationships between the tumor and critical functional structures such as nerves, esophagus, and trachea were carefully evaluated to prevent injury.

One percent lidocaine was used for local anesthesia at the puncture site and perithyroidal area. A trans-isthmic approach was used for the RFA $(15,16)$. The initial RF power ranged from 15 to $40 \mathrm{~W}$, according to the size of the electrode tip. If a transient hyperechoic zone did not form at the electrode tip within 5-10 s, the RF power was increased in 5-10 $\mathrm{W}$ increments, up to $25-50 \mathrm{~W}$. The electrode tip was fixed in the center of the tumor when the tumor was small, whereas larger tumors were treated unit by unit, using a moving-shot technique (13,17-19). According to the situation, during or after procedure, a 25-gauge needle was used to inject a cold lidocaine solution between the tumor and critical functional structures to prevent thermal injury and obtain a safety margin, the so-called hydrodissection technique $(9,20)$. To prevent marginal recurrence, a sufficient quantity (at least $2 \mathrm{~mm}$ ) of adjacent normal thyroid tissue was also ablated. If the tumor was located in a subcapsular area, we added hydrodissection to the affected site to ensure safety. The presence of any complications occurring during and immediately after ablation was carefully evaluated, and all patients were observed for four to five hours in the hospital after ablation.

\section{Postablation assessment}

Patients were followed using US and clinical evaluations at 1, 6, and 12 months, and then every 12 months afterward. The follow-up US examinations included measurement of the tumor volume and its orthogonal three-dimensional maximal diameters to evaluate local tumor progression (recurrence and growth of the ablated tumor), and evaluation of newly developed cancers (detection of new cancer other than the ablated tumor, with cytological confirmation), LN or distant metastasis, and delayed surgery (any cause of thyroid surgery during the follow-up period). The volume reduction rate was calculated as follows: volume reduction ratio $(\mathrm{VRR})=([$ initial volume - final volume] $\times 100$ )/initial volume $(13)$. CT was performed in all patients at two and four years after ablation to 
check for LN metastasis. If an abnormal radiological finding was apparent on the US and CT, a US-guided biopsy was performed on the lesion. A thyroid function test was performed immediately after the ablation, and then at 2, 6, and 12 months afterward.

Additional RFA was performed in those cases where the first RFA did not completely cover the tumor margins, and where new cancer had appeared on follow-up. The treatment efficacy was evaluated according to serial change in the mean VRR and complete disappearance (18). Complications during the procedure or follow-up were assessed using the reporting standards of the Society of Interventional Radiology (21). Both early (within 30 days after RFA) and delayed (>30 days after RFA) complications were evaluated (22).

\section{Results}

The characteristics of the study cohort, tumors, and RFA parameters are described in Table 1. Eighty-four PTMCs in 74 patients were evaluated in this study. The mean follow-up duration after RFA was $72 \pm 18$ months (range, 60-124 months). The median largest tumor diameter was $0.4 \mathrm{~cm}$ (range, $0.3-0.99 \mathrm{~cm}$ ), and the median volume was $0.02 \mathrm{~mL}$ (range, $0.001-0.234 \mathrm{~mL}$ ). Among the 84 tumors, 52 had a largest diameter between 0.3 and $0.5 \mathrm{~cm}$, while the other 32 tumors were $\geq 0.5 \mathrm{~cm}$. The mean number of RFA treatment sessions per tumor was $1.2 \pm 0.4$.

Table 1. Study Cohort Characteristics

\begin{tabular}{|c|c|}
\hline Characteristics & Data \\
\hline \multicolumn{2}{|l|}{ Patients $(n=74)$} \\
\hline Female:male, no. $(\%)$ & 66 (89.2):8 (10.8) \\
\hline Mean age $\pm S D$, years & $46 \pm 12$ \\
\hline $\begin{array}{l}\text { Mean follow-up } \pm S D \\
\text { months }\end{array}$ & $72 \pm 18$ \\
\hline \multicolumn{2}{|l|}{ PTMCs $(n=84)$} \\
\hline$<0.5 \mathrm{~cm}: \geq 0.5 \mathrm{~cm}$, no. $(\%)$ & $52(61.9): 32(38.1)$ \\
\hline \multicolumn{2}{|l|}{ Location, no. (\%) } \\
\hline Right & $33(39.3)$ \\
\hline Left & $44(52.4)$ \\
\hline Isthmus & $7(8.3)$ \\
\hline $\begin{array}{l}\text { Median largest diameter, } \\
\text { cm (range) }\end{array}$ & $0.4(0.3-0.99)$ \\
\hline Median volume, $\mathrm{mL}$ & $0.02(0.001-0.234)$ \\
\hline \multicolumn{2}{|l|}{ Radiofrequency ablation } \\
\hline $\begin{array}{l}\text { RF sessions, one:two, } \\
\text { no. }(\%)\end{array}$ & $71(84.5): 13(15.5)$ \\
\hline Total number of RF sessions & 97 \\
\hline Mean RF sessions $\pm \mathrm{SD}$ & $1.2 \pm 0.4$ \\
\hline Median RF power, W & 20 (Range, 20-40) \\
\hline $\begin{array}{l}\text { Median ablation time, } \\
\text { seconds }\end{array}$ & 151 (Range, 30-326) \\
\hline Median total energy, $\mathrm{J}$ & 3150 (Range, 600-7880) \\
\hline $\begin{array}{l}\text { Median delivered } \\
\text { energy }(\mathrm{J}) / \mathrm{mL}\end{array}$ & $\begin{array}{c}185,237 \\
\text { (Range, } 13,088-4,716,379)\end{array}$ \\
\hline \multicolumn{2}{|l|}{ Active tip size, no. (\%) } \\
\hline $5 \mathrm{~mm}$ & $92(94.8)$ \\
\hline $7 \mathrm{~mm}$ & $4(4.1)$ \\
\hline $10 \mathrm{~mm}$ & $1(1)$ \\
\hline
\end{tabular}

PTMC, papillary thyroid microcarcinoma; RFA, radiofrequency ablation; SD, standard deviation.
All ablated tumors completely disappeared during the 60-month follow-up. The complete disappearance rates were $34.5 \%, 74.1 \%, 98.8 \%, 98.8 \%, 98.8 \%$, and $100 \%$ at 6 , 12, 24, 36, 48, and 60 months, respectively (Supplementary Table S1). A representative case and the mean VRR for the study cohort are presented in Figures 1 and 2, respectively. The tumor volumes increased immediately after RFA and then decreased gradually. At 24 months, the mean VRR was near to $100 \%$, and this VRR was maintained until the 60month follow-up. There was no local tumor progression and no LN or distant metastasis, and no patients underwent delayed surgery. However, there were four new cancers in three patients in the remaining thyroid gland, with these being separate from the initially ablated tumor. These new cancers were also successfully ablated by RFA. There were four complications, which consisted of three minor complications $(4.1 \%, 3$ of 74 patients: two hematomas with immediate recovery and one first-degree burn) and one major complication $(1.4 \%, 1$ of 74 patients: a voice change that had recovered at the 2-month follow-up). However, there was no RFA-related life-threatening immediate complication, and no delayed complications during the mean follow-up period of 72 months.

\section{Discussion}

This study presents long-term follow-up results over $>5$ years for RFA treatment of 84 PTMCs. The RFA resulted in the complete disappearance of all ablated tumors, with no local tumor progression, no LN or distant metastasis, and no need for delayed surgery because of patient anxiety during the long-term follow-up period. Although there were four new cancers (separated from the initially ablated tumor) in three patients in the remaining thyroid gland, these were also successfully ablated by RFA. The major complication rate was $1.4 \%$ (1/74), and there were no life-threatening or delayed complications. Therefore, RFA was an effective and safe treatment for PTMC.

In previous studies, several thermal ablation methods showed favorable local control efficacy for treating low-risk PTMCs, with VRR of $80-100 \%$ and no local tumor recurrences or distant metastases $(9,15,23-31)$. These studies reported only two cases of LN metastasis (1/64 in Zhang et al., $1 / 37$ in Ji et al., both studies using laser ablation) and one newly developed cancer (1/185 in Teng et al., a study using microwave ablation) during follow-up after ablation $(27,29,30)$. However, longer-term results are required for several reasons. First, most of the published studies had relatively short-term follow-up or small study cohorts. The longest follow-up RFA treatment results reported are those by Kim et al., who reported four-year follow-up results, but only for four patients (25). Second, PTMC is typically indolent, making it difficult to ascertain durable efficacy on short-term follow-up (1). Third, long-term follow-up provides added information on LN metastasis, as PTMC is known to frequently result in $\mathrm{LN}$ metastases in the central compartment, which cannot easily be detected preoperatively $(32,33)$. Finally, the current thyroid guidelines do not recommend RFA for the first-line treatment of PTMC, but as a second-line option. The European Thyroid Association Guidelines suggest that in patients with refractory primary cancer requiring treatment, RFA should only be performed at 
FIG. 1. Pre-RFA and post-RFA follow-up example of PTMC. The proven hypoechoic PTMC located on right side of the isthmus with spiculated margin in a 29 years old female (pre-RFA). Serial follow-up after ablation demonstrated the large ablation zone, including the primary cancer gradually decreased, and eventually disappeared. PTMC, papillary thyroid microcarcinoma; RFA, radiofrequency ablation.
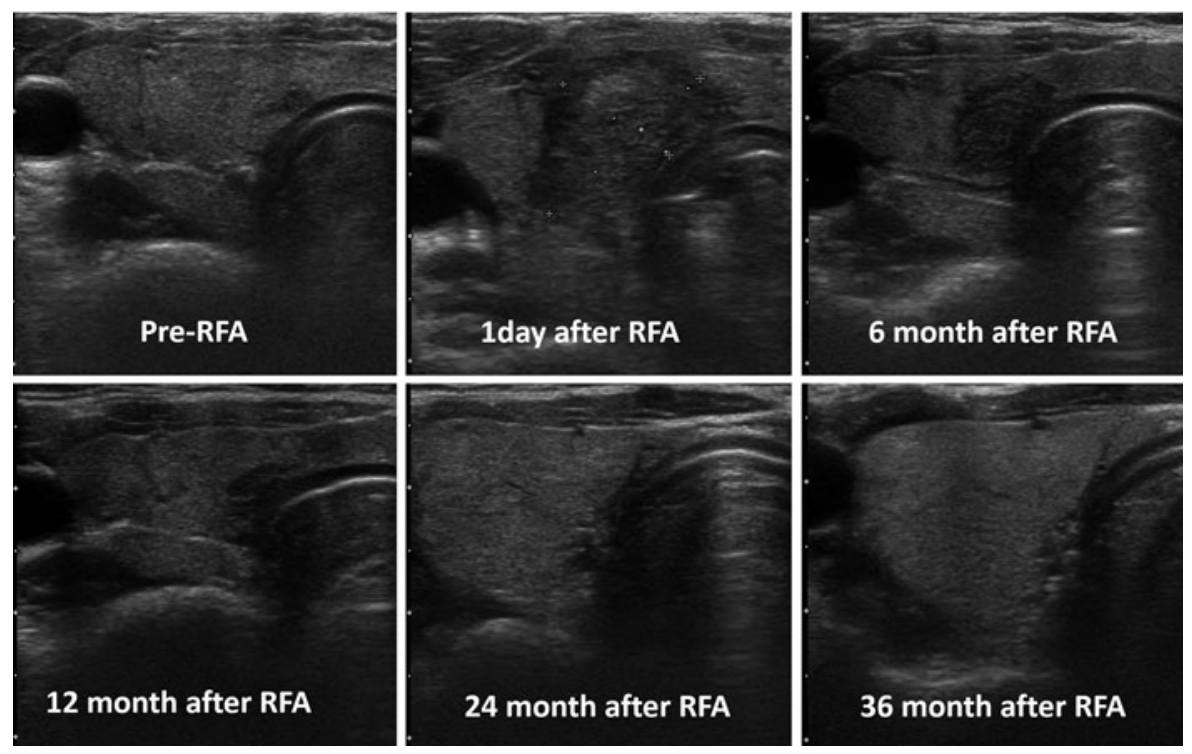

the site of the disease or a metastasis that is growing (34). The 2017 Korean Radiofrequency Ablation Guideline recommends RFA for patients with primary thyroid cancer who refuse surgery or who cannot undergo an operation, and that thermal ablations can be considered as an alternative (20). Nevertheless, they commonly agree on the effectiveness and safety for local control of tumors. Therefore, confidence in the long-term results for the treatment of PTMC by thermal ablation may be needed. This study reports the longest follow-up results for thermal ablation for treating low-risk PTMC, demonstrating favorable efficacy for patients with a mean follow-up duration of 72 months, and all with $>5$ years of follow-up. It is, however, important to note that some guidelines do not recommend that such small tumors need to be biopsied.
Recently, AS has been suggested as a first-line management option for low-risk PTMC $(2,35,36)$. A systematic review and meta-analysis showed favorable results for AS, with only a small proportion of tumors showing size enlargement $(5.3 \%)$ and $\mathrm{LN}$ metastasis (1.6\%) during 5-year follow-up (6). However, the study also mentioned the limitations of AS. First, a large proportion (range, 8.7-32\%) of patients underwent delayed surgery during follow-up. Moreover, many of the patients suffered from anxiety, as more than half of their symptoms were not related to tumor enlargement or LN metastasis. In a systematic review that presented results for 503 low-risk PTMCs in 470 patients treated by thermal ablation, there was no local tumor recurrence or distant metastasis (7), although two patients (0.4\%) suffered LN metastasis, and one patient $(0.2 \%)$ developed a new PTMC,
FIG. 2. Serial mean volume reduction rates during long-term follow-up. The values of mean volume reduction rates \pm standard deviation.

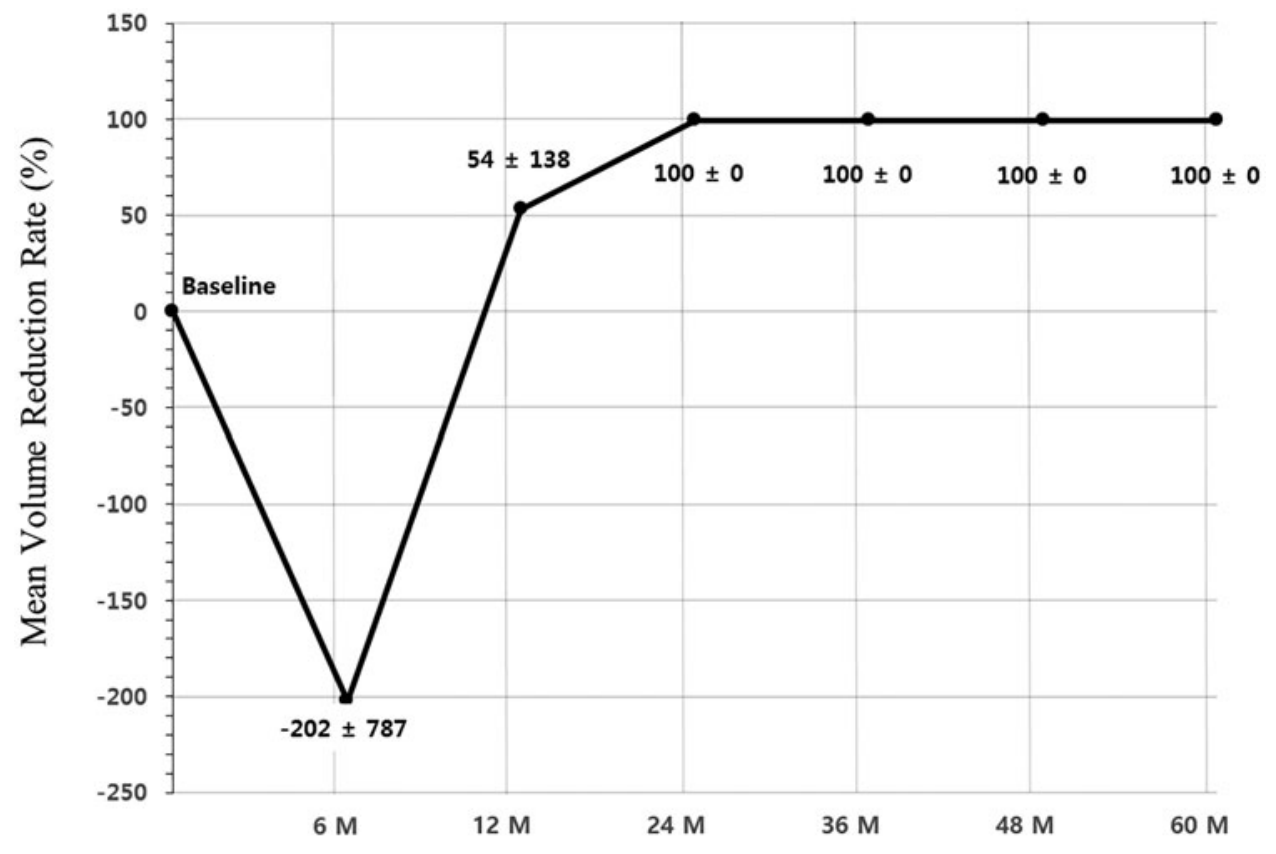


which was successfully treated by additional ablation. In addition, only five patients $(1.1 \%)$ underwent delayed surgery after ablation, two patients with LN metastasis and three additional patients for unknown reasons. Similarly, in this study covering 84 tumors, we found no local tumor progression, no LN or distant metastasis, and no delayed surgery due to anxiety over a long-term follow-up period of more than five years. Although a direct comparison study is not available and the original published studies included only PTMCs, we believe that thermal ablation may alleviate or eliminate patient anxiety by treating the primary tumor.

In contrast to our results, there are a few reports describing unsatisfactory results for ablation of low-risk PTMC. For example, Ma et al. reported the results of 12 papillary thyroid carcinoma patients who were treated by thermal ablation (37). The cytological results after surgery demonstrated residual cancers and LN metastasis. However, their inclusion criteria were nonlow-risk PTMC ( $>1 \mathrm{~cm}$, demonstrated capsule invasion and LN metastasis), and we suggest that only low-risk PTMC should be considered for treatment by thermal ablation.

Although there are a few discrepancies in the definition of low-risk PTMC among the guidelines, low-risk PTMC is currently considered suitable for AS (38-42). A systematic review suggested the importance of strict inclusion criteria for thermal ablation for PTMC, criteria that can be adopted from AS (7). In addition, to verify the diagnosis of low-risk PTMC and rule out LN metastasis before ablation, detailed pretreatment imaging work-up is required, including contrastenhanced CT (43). Therefore, RFA for primary cancer should be performed only in low-risk PTMC with accurate staging of patients. If other studies show similar efficacy of RFA treatment for low-risk PTMC, RFA can be considered as an alternative to AS.

This study has several limitations. First, it is subject to a selection bias due to the retrospective study design. A further long-term multicenter prospective study is needed to confirm the results, even though our study reports the longest follow-up results to our knowledge. Second, in enrolling patients with long-term follow-up data of more than five years, we inevitably included tumors treated in the early experience period of the RFA performer, which could have affected the complication rate. However, there was no life-threatening immediate complication and no delayed complications during the mean followup period of 72 months. Third, we included tumors diagnosed by FNA cytology before RFA that might have been false positive. Finally, we assessed the presence of extrathyroidal extension by imaging, not by histopathology.

In conclusion, RFA is effective and safe for long-term local tumor control for low-risk PTMC. RFA could be considered a treatment option for low-risk PTMC.

\section{Author Disclosure Statement}

No competing financial interests exist.

\section{Funding Information}

No funding was received.

\section{Supplementary Material}

Supplementary Table S1

\section{References}

1. Oda H, Miyauchi A, Ito Y, Yoshioka K, Nakayama A, Sasai H, Masuoka H, Yabuta T, Fukushima M, Higashiyama T, Kihara M, Kobayashi K, Miya A 2016 Incidences of unfavorable events in the management of low-risk papillary microcarcinoma of the Thyroid by Active Surveillance Versus Immediate Surgery. Thyroid 26:150-155.

2. Ito $\mathrm{Y}$, Miyauchi A, Inoue H, Fukushima M, Kihara M, Higashiyama T, Tomoda C, Takamura Y, Kobayashi K, Miya A 2010 An observational trial for papillary thyroid microcarcinoma in Japanese patients. World J Surg 34: 28-35.

3. Ito Y, Miyauchi A, Kihara M, Higashiyama T, Kobayashi K, Miya A 2014 Patient age is significantly related to the progression of papillary microcarcinoma of the thyroid under observation. Thyroid 24:27-34.

4. Oh HS, Ha J, Kim HI, Kim TH, Kim WG, Lim DJ, Kim TY, Kim SW, Kim WB, Shong Y, Chung JH, Baek JH 2018 Active surveillance of low-risk papillary thyroid microcarcinoma: a multi-center cohort study in Korea. Thyroid: official journal of the American Thyroid Association.

5. Tuttle RM, Haugen B, Perrier ND 2017 Updated American Joint Committee on Cancer/tumor-node-metastasis staging system for differentiated and anaplastic thyroid cancer (eighth edition): what changed and why? Thyroid 27:751756.

6. Cho SJ, Suh CH, Baek JH, Chung SR, Choi YJ, Chung KW, Shong YK, Lee JH 2019 Active surveillance for small papillary thyroid cancer: a systematic review and metaanalysis. Thyroid 29:1399-1408.

7. Cho SJ, Baek JH, Chung SR, Choi YJ, Lee JH 2019 Thermal ablation for small papillary thyroid cancer: a systematic review. Thyroid 29:1774-1783.

8. Choi Y, Jung SL 2019 Efficacy and safety of thermal ablation techniques for the treatment of primary papillary thyroid microcarcinoma: a systematic review and metaanalysis. Thyroid 30:720-731..

9. Lim HK, Cho SJ, Baek JH, Lee KD, Son CW, Son JM, Baek SM 2019 US-guided radiofrequency ablation for lowrisk papillary thyroid microcarcinoma: efficacy and safety in a large population. Korean J Radiol 20:1653-1661.

10. Na DG, Baek JH, Jung SL, Kim JH, Sung JY, Kim KS, Lee JH, Shin JH, Choi YJ, Ha EJ, Lim HK, Kim SJ, Hahn SY, Lee KH, Choi YJ, Youn I, Kim YJ, Ahn HS, Ryu JH, Baek SM, Sim JS, Jung CK, Lee JH 2017 Core needle biopsy of the thyroid: 2016 Consensus Statement and Recommendations from Korean Society of Thyroid Radiology. Korean J Radiol 18:217-237.

11. Ha EJ, Lim HK, Yoon JH, Baek JH, Do KH, Choi M, Choi JA, Lee M, Na DG 2018 Primary imaging test and appropriate biopsy methods for thyroid nodules: guidelines by Korean Society of Radiology and National Evidence-Based Healthcare Collaborating Agency. Korean J Radiol 19: 623-631.

12. Kim HJ 2017 Updated guidelines on the preoperative staging of thyroid cancer. Ultrasonography (Seoul, Korea) 36:292-299.

13. Jung SL, Baek JH, Lee JH, Shong YK, Sung JY, Kim KS, Lee D, Kim JH, Baek SM, Sim JS, Na DG 2018 Efficacy and safety of radiofrequency ablation for benign thyroid nodules: a prospective multicenter study. Korean J Radiol 19:167-174.

14. Baek JH, Kim YS, Sung JY, Choi H, Lee JH 2011 Locoregional control of metastatic well-differentiated thyroid 
cancer by ultrasound-guided radiofrequency ablation. AJR Am J Roentgenol 197:W331-W336.

15. Jeong SY, Baek JH, Choi YJ, Chung SR, Sung TY, Kim WG, Kim TY, Lee JH 2018 Radiofrequency ablation of primary thyroid carcinoma: efficacy according to the types of thyroid carcinoma. Int J Hyperthermia 34:611-616.

16. Na DG, Lee JH, Jung SL, Kim JH, Sung JY, Shin JH, Kim EK, Lee JH, Kim DW, Park JS, Kim KS, Baek SM, Lee Y, Chong S, Sim JS, Huh JY, Bae JI, Kim KT, Han SY, Bae MY, Kim YS, Baek JH 2012 Radiofrequency ablation of benign thyroid nodules and recurrent thyroid cancers: consensus statement and recommendations. Korean $\mathrm{J}$ Radiol 13:117-125.

17. Baek JH, Kim YS, Lee D, Huh JY, Lee JH 2010 Benign predominantly solid thyroid nodules: prospective study of efficacy of sonographically guided radiofrequency ablation versus control condition. AJR Am J Roentgenol 194:11371142.

18. Jeong WK, Baek JH, Rhim H, Kim YS, Kwak MS, Jeong HJ, Lee D 2008 Radiofrequency ablation of benign thyroid nodules: safety and imaging follow-up in 236 patients. Eur Radiol 18:1244-1250.

19. Park HS, Baek JH, Park AW, Chung SR, Choi YJ, Lee JH 2017 Thyroid radiofrequency ablation: updates on innovative devices and techniques. Korean J Radiol 18:615-623.

20. Kim JH, Baek JH, Lim HK, Ahn HS, Baek SM, Choi YJ, Choi YJ, Chung SR, Ha EJ, Hahn SY, Jung SL, Kim DS, Kim SJ, Kim YK, Lee CY, Lee JH, Lee KH, Lee YH, Park JS, Park H, Shin JH, Suh CH, Sung JY, Sim JS, Youn I, Choi M, Na DG 20182017 Thyroid radiofrequency ablation guideline: Korean Society of Thyroid Radiology. Korean J Radiol 19:632-655.

21. Ahmed M, Solbiati L, Brace CL, Breen DJ, Callstrom MR, Charboneau JW, Chen MH, Choi BI, de Baere T, Dodd GD III, Dupuy DE, Gervais DA, Gianfelice D, Gillams AR, Lee FT, Jr, Leen E, Lencioni R, Littrup PJ, Livraghi T, Lu DS, McGahan JP, Meloni MF, Nikolic B, Pereira PL, Liang P, Rhim H, Rose SC, Salem R, Sofocleous CT, Solomon SB, Soulen MC, Tanaka M, Vogl TJ, Wood BJ, Goldberg SN 2014 Image-guided tumor ablation: standardization of terminology and reporting criteria-a 10-year update. J Vasc Interv Radiol 25:1691-1705.e1694.

22. Baek JH, Lee JH, Sung JY, Bae JI, Kim KT, Sim J, Baek SM, Kim YS, Shin JH, Park JS, Kim DW, Kim JH, Kim EK, Jung SL, Na DG 2012 Complications encountered in the treatment of benign thyroid nodules with US-guided radiofrequency ablation: a multicenter study. Radiology 262:335-342.

23. Yue W, Wang S, Yu S, Wang B 2014 Ultrasound-guided percutaneous microwave ablation of solitary T1N0M0 papillary thyroid microcarcinoma: initial experience. Int $\mathbf{J}$ Hyperthermia 30:150-157.

24. Zhang M, Luo Y, Zhang Y, Tang J 2016 Efficacy and safety of ultrasound-guided radiofrequency ablation for treating low-risk papillary thyroid microcarcinoma: a prospective study. Thyroid 26:1581-1587.

25. Kim JH, Baek JH, Sung JY, Min HS, Kim KW, Hah JH, Park DJ, Kim KH, Cho BY, Na DG 2017 Radiofrequency ablation of low-risk small papillary thyroidcarcinoma: preliminary results for patients ineligible for surgery. Int $\mathrm{J}$ Hyperthermia 33:212-219.

26. Zhou W, Jiang S, Zhan W, Zhou J, Xu S, Zhang L 2017 Ultrasound-guided percutaneous laser ablation of unifocal
T1N0M0 papillary thyroid microcarcinoma: preliminary results. Eur Radiol 27:2934-2940.

27. Zhang L, Zhou W, Zhan W, Peng Y, Jiang S, Xu S 2018 Percutaneous laser ablation of unifocal papillary thyroid microcarcinoma: utility of conventional ultrasound and contrast-enhanced ultrasound in assessing local therapeutic response. World J Surg 42:2476-2484.

28. Teng D, Sui G, Liu C, Wang Y, Xia Y, Wang H 2018 Long-term efficacy of ultrasound-guided low power microwave ablation for the treatment of primary papillary thyroid microcarcinoma: a 3-year follow-up study. J Cancer Res Clin Oncol 144:771-779.

29. Teng DK, Li HQ, Sui GQ, Lin YQ, Luo Q, Fu P, Du JR, Jin CX, Wang H 2019 Preliminary report of microwave ablation for the primary papillary thyroid microcarcinoma: a large-cohort of 185 patients feasibility study. Endocrine 64: 109-117.

30. Ji L, Wu Q, Gu J, Deng X, Zhou W, Fan X, Zhou F 2019 Ultrasound-guided percutaneous laser ablation for papillary thyroid microcarcinoma: a retrospective analysis of 37 patients. Cancer Imaging 19:16.

31. Li J, Liu Y, Liu J, Qian L 2018 Ultrasound-guided percutaneous microwave ablation versus surgery for papillary thyroid microcarcinoma. Int J Hyperthermia 34:653-659.

32. Wada N, Duh QY, Sugino K, Iwasaki H, Kameyama K, Mimura T, Ito K, Takami H, Takanashi Y 2003 Lymph node metastasis from 259 papillary thyroid microcarcinomas: frequency, pattern of occurrence and recurrence, and optimal strategy for neck dissection. Ann Surg 237:399-407.

33. Roh JL, Kim JM, Park CI 2008 Central cervical nodal metastasis from papillary thyroid microcarcinoma: pattern and factors predictive of nodal metastasis. Ann Surg Oncol 15:2482-2486.

34. Fugazzola L, Elisei R, Fuhrer D, Jarzab B, Leboulleux S, Newbold K, Smit J 20192019 European Thyroid Association Guidelines for the treatment and follow-up of advanced radioiodine-refractory thyroid cancer. Eur Thyroid J 8:227-245.

35. Tufano RP, Clayman G, Heller KS, Inabnet WB, Kebebew E, Shaha A, Steward DL, Tuttle RM 2015 Management of recurrent/persistent nodal disease in patients with differentiated thyroid cancer: a critical review of the risks and benefits of surgical intervention versus active surveillance. Thyroid 25:15-27.

36. Sakai T, Sugitani I, Ebina A, Fukuoka O, Toda K, Mitani H, Yamada K 2019 Active surveillance for T1bN0M0 papillary thyroid carcinoma. Thyroid 29:59-63.

37. Ma B, Wei W, Xu W, Wang Y, Guan H, Fan J, Zhao Z, Wen D, Yang S, Wang Y, Chang B, Ji Q 2018 Surgical confirmation of incomplete treatment for primary papillary thyroid carcinoma by percutaneous thermal ablation: a retrospective case review and literature review. Thyroid 28: 1134-1142.

38. Haugen BR, Alexander EK, Bible KC, Doherty GM, Mandel SJ, Nikiforov YE, Pacini F, Randolph GW, Sawka AM, Schlumberger M, Schuff KG, Sherman SI, Sosa JA, Steward DL, Tuttle RM, Wartofsky L 20162015 American Thyroid Association Management Guidelines for adult patients with thyroid nodules and differentiated thyroid cancer: the American Thyroid Association Guidelines Task Force on Thyroid Nodules and Differentiated Thyroid Cancer. Thyroid 26:1-133. 
39. Gharib H, Papini E, Garber JR, Duick DS, Harrell RM, Hegedus L, Paschke R, Valcavi R, Vitti P 2016 American Association of Clinical Endocrinologists, American College of Endocrinology, and Associazione Medici Endocrinologi Medical Guidelines for Clinical Practice for the Diagnosis and Management of Thyroid Nodules-2016 update. Endocr Pract 22:622-639.

40. Russ G, Bonnema SJ, Erdogan MF, Durante C, Ngu R, Leenhardt L 2017 European Thyroid Association Guidelines for ultrasound malignancy risk stratification of thyroid nodules in adults: the EU-TIRADS. Eur Thyroid J 6:225-237.

41. Tessler FN, Middleton WD, Grant EG, Hoang JK, Berland LL, Teefey SA, Cronan JJ, Beland MD, Desser TS, Frates MC, Hammers LW, Hamper UM, Langer JE, Reading CC, Scoutt LM, Stavros AT 2017 ACR Thyroid Imaging, Reporting and Data System (TI-RADS): white paper of the ACR TI-RADS Committee. J Am Coll Radiol 14:587-595.

42. Shin JH, Baek JH, Chung J, Ha EJ, Kim JH, Lee YH, Lim HK, Moon WJ, Na DG, Park JS, Choi YJ, Hahn SY, Jeon SJ, Jung SL, Kim DW, Kim EK, Kwak JY, Lee CY, Lee
HJ, Lee JH, Lee JH, Lee KH, Park SW, Sung JY 2016 Ultrasonography diagnosis and imaging-based management of thyroid nodules: revised Korean Society of Thyroid Radiology Consensus Statement and Recommendations. Korean J Radiol 17:370-395.

43. Suh CH, Baek JH 2017 Performance of CT in the preoperative diagnosis of cervical lymph node metastasis in patients with papillary thyroid cancer: a systematic review and meta-analysis. AJNR Am J Neuroradiol 38:154-161.

Address correspondence to:

Sun Mi Baek, MD

Department of Radiology

Haeundae Sharing and Happiness Hospital 502, Jwadongsunhwan-ro, Haeundae-gu Busan 48101 Republic of Korea

E-mail:nhbsm@naver.com 